\title{
THE PHYSIOLOGICAL BASIS OF REFLUX OESOPHAGITIS IN SLIDING HIATAL DIAPHRAGMATIC HERNIA
}

\author{
JOHN A. AYLWIN \\ From the Department of Thoracic Surgery, the General Infirmary, Leeds
}

(RECEIVED FOR PUBLICATION JULY 14, 1952)

The rational treatment of each patient with ulceration of the oesophagus above a diaphragmatic hernia of the stomach would be easier if more was known about the aetiology of this complex condition.

Experimentally the squamous epithelium of the oesophagus shows no real resistance to peptic digestion (Selye, 1938), but clinically, when valvular function at the cardia is lost, the damage to the oesophagus which follows varies widely in different individuals and may be completely absent. A bedside experiment has been designed to clarify the obvious difference between some patients with hernia and reflux who, in a few months, develop obstruction from peptic stenosis of the oesophagus, and others who, for 30 years with an unblemished guilet, suffer only mild social embarrassment after dinner. Between these extremes there is a large group in whom mild oesophagitis with occasional aggravation has been present for years without a stricture forming; yet in all three groups there is no gross difference in the sliding hernia. As this variable damage has prognostic importance in the management of such a common condition, it calls for an explanation of how and why it arises.

In the last two years 50 patients from these dissimilar groups (Table I) have been studied under

TABLE I

THE 50 PATIENTS INCLUDED IN THE SERIES

\begin{tabular}{|c|c|c|c|c|c|c|c|c|c|c|}
\hline \multirow[t]{2}{*}{ No. and Sex } & \multicolumn{6}{|c|}{ Age } & \multicolumn{4}{|c|}{$\begin{array}{c}\text { Degree of } \\
\text { Oesophagitis }\end{array}$} \\
\hline & 总 & î̀ & $\stackrel{i}{i}$ & $\mid \begin{array}{l}q \\
q\end{array}$ & 点 & $\stackrel{+}{8}$ & ż & 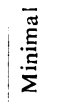 & 这 & 它苛 \\
\hline $\begin{array}{l}28 \text { women } \\
20 \text { men... } \\
2 \text { infants }\end{array}$ & 2 & 1 & 7 & 11 & 20 & 9 & 19 & 12 & 12 & 7 \\
\hline
\end{tabular}

standard conditions, so that the digestive quality of juices collected from the gullet could be compared with the damage seen at oesophagoscopy. Enzyme activity alone was found responsible for the oesophagitis, and its severity depends upon different physiological factors which modify both $\omega_{\infty}^{\omega}$ the peptic power of the material bathing the gullet 을 and its defences. These factors include the diaphragmatic hiatus, vagus nerves, oesophageal 3 and salivary secretions, as well as the distribution of gastric glands within the hernia and the func- 3 tion of the cardiac sphincter above it. All are $\vec{\varphi}$ involved in different ways and will be discussed in on turn.

By showing how progressive damage occurs, it is hoped that this work will be helpful in deciding when to advise early surgical reduction for the poor-risk patients seen so often with hiatus hernia before the onset of rigidity or stenosis makes it necessary to carry out the more formidable oper- $\bar{c}$ ation of resection. Such patients should be singled out from the less serious group, in whom surgery is so optional that it may be postponed, either indefinitely or until the patient becomes a better candidate for operation, by reduction of surplus weight or other means.

Method fOr ANAlysis of Oesophageal Juices

During the night sleep affords a suitable interval for standardized observation, and it also gives natural control of the many complex factors which modify 윽 the quality and quantity of the accumulated secretions $D$ in the oesophagus. These juices can then be collected by continuous aspiration, but if the results are to be reliable for comparison this procedure must not cause 0 reflex vagal stimulation from the naso-pharynx or $N$ oesophagus. To this end a home-made tube was N designed (Fig. 1). Made from pliable polythene, it $\omega$ has a bore of $1 \mathrm{~mm}$. and contains a short length of lead wire sealed in below by a smooth drop of 6 hardened nail varnish; this tip aids both introduction $\Phi$ and radiological observation. Four holes are pro- $\stackrel{?}{?}$ vided at the lower end, and are made with a chest- $T$ aspirating needle converted into a miniature cork- $\vec{O}$ borer by grinding its point to a uniform cutting $\overrightarrow{\mathbb{D}}$ cylinder. The tube is adapted to a Stedmann $\frac{\mathbb{D}}{\mathbb{D}}$ empyema pump by an M.R.C. transfusion cannula, $\varrho$ and, once passed, the patient becomes unaware of itse presence. 


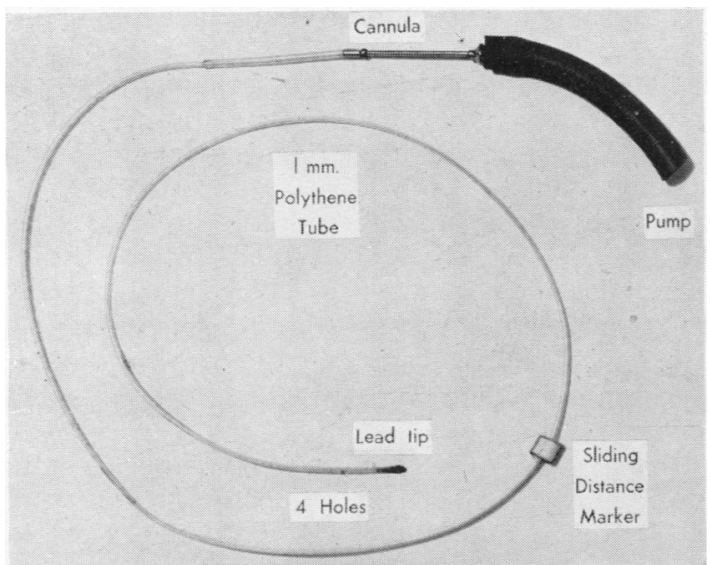

FIG. 1.-Oesophageal juice collecting-tube.

Each patient has a standard light fluid meal at 6 p.m. At 9 p.m. "decicaine" is applied to the nasal mucosa, and the tube passed through the nose until its end lies just above the cardia. To reduce contamination by saliva, suction is withheld until the patient is sleeping, and it is discontinued on waking. The negative pressure used depends on the consistency of the secretions, and is adjusted until a flow is obtained, usually at about minus 20 to $40 \mathrm{~cm}$. of water. All subjects have two pillows, but no other restrictions on posture are imposed, so that samples are taken during a normal night's sleep. The length of tube to be passed beyond the nose is measured by adding $3 \mathrm{~cm}$. to the oesophagoscopic distance of the cardia from the upper incisors, and a sliding marker on the tube is adjusted so that it will lie at the nostril when the tube is correctly placed. Trial and error have shown that this method places the tip of the tube just above the displaced cardia, as seen by a barium swallow in the horizontal position. The validity of each test is accepted only if the tube is patent on removal and a lateral radiograph has shown its tip in the right place (Fig. 2).

That this method is as free as possible from reflex stimulation of vagal secretion was demonstrated when, by accident, one patient had the tube passed through the larynx into the bronchial tree, where it stayed overnight without irritation until the usual radiological check on its position next morning.

The juice collected is stored in a refrigerator, and tested at noon, so that deterioration in enzyme activity is minimized and remains the same for each test. Colour, volume, and the presence of bile, blood, food residue, and mucus are recorded. The last is graded visually for quantity, as no satisfactory measure of mucus is known.

Universal indicator dye is used to measure $p \mathrm{H}$ and Fuld and Levison's (1907) method for pepsin as modified by Mathews (1925). For the latter the secretion is first acidified and then its digestive power is compared at $37^{\circ} \mathrm{C}$. with that of freshly made and acidi- fied $0.1 \%$ standard pepsin B.P., when acting upon $1 \%$ solution of "edestin," a pure form of protein. This method was tested for accuracy over the range of dilutions involved and found satisfactory.

The severity of oesophagitis was assessed within one week of making the juice test, because symptoms vary in intensity, but the appearances were not noticeably different from those present when the symptoms were of different severity at some previous endoscopy.

\section{Results}

These are tabulated in Figs. 3, 4, and 5, and the following have been the main findings which show the close correlation of nocturnal peptic activity with the grade of damage in the oesophagus.

When juices were collected more than once from a few patients, the results of analysis were unchanged even when taken months apart.

In Group 1, with no oesophagitis, a valid dry test was obtained in two-thirds of the patients, but in the remainder a reasonable volume of juice was collected. This contained very little or no pepsin, and the $p H$ was always near neutral, so that enzyme activity was impossible. Mucus was absent from the juice of this group.

In Group 2, with minimal oesophagitis, just redness and oedema but no ulceration, the characteristic findings were a good volume with plentiful mucus and pepsin concentrations varying from 0.07 to $0.32 \%$. These figures roughly correspond to those seen during normal gastric response to food. In only one case was a $p H$ found within

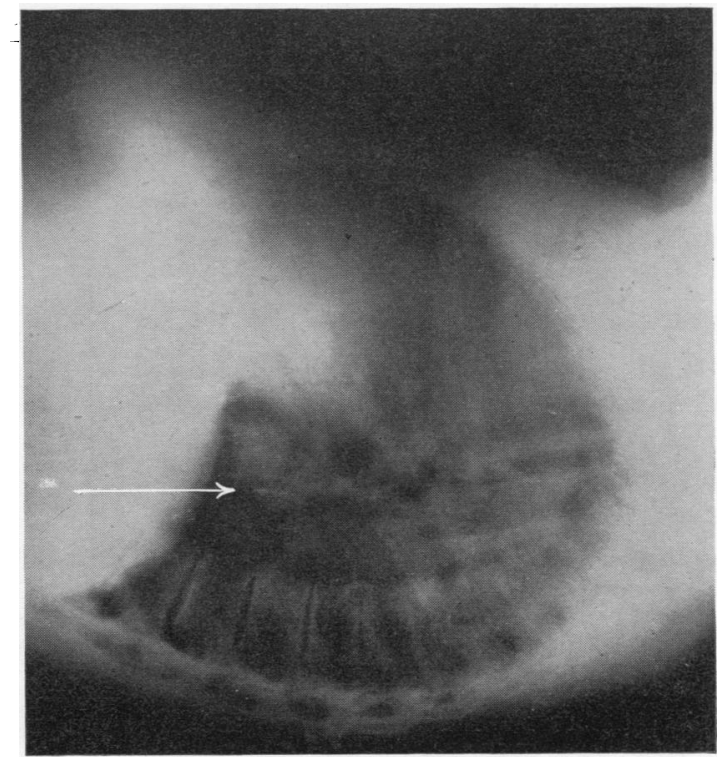

FIG. 2.-Lateral radiograph (supine) showing correct position of collecting-tube tip above a small hernia. 


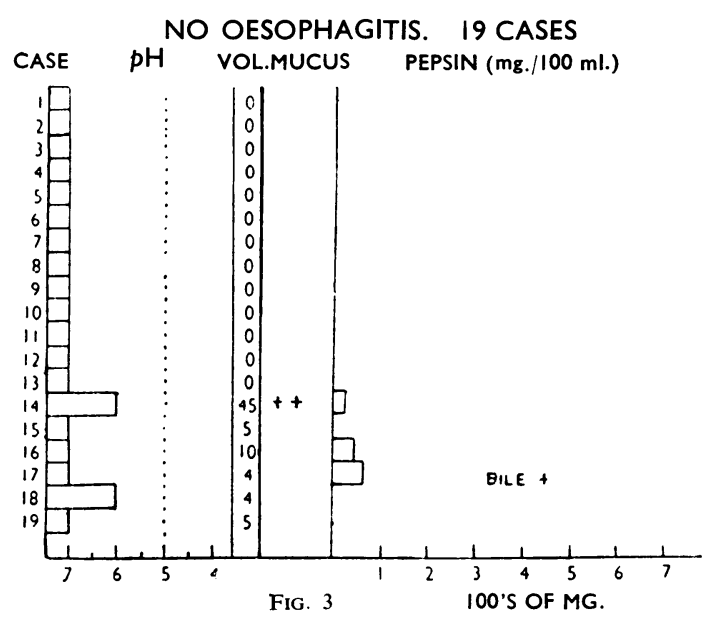

MINIMAL OESOPHAGITIS. -11 CASES
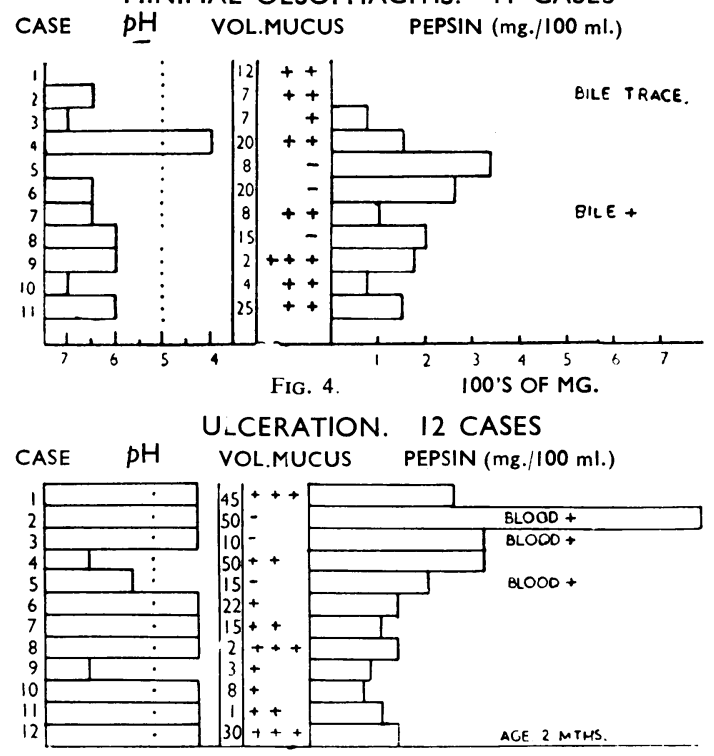

STRICTURIS. 7 CASES

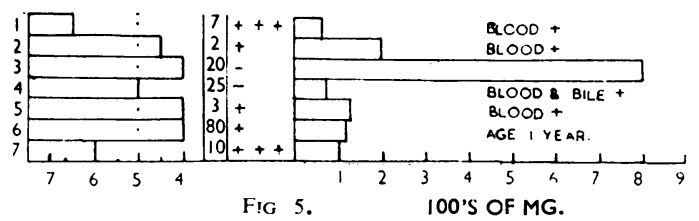

FIGs. 3-5.-The peptic power of nocturnal oesophageal juices grouped according to grade of damage seen at endoscopy Dotted line $=p \mathrm{H}$ required for minimal activation of pepsin $\mathrm{Vol} .=\mathrm{ml}$. of juice collected during sleep.

the range required for pepsin activation ( $p \mathrm{H} \mathrm{5-2)}$; in all the rest it failed to follow pepsin levels and lay between 7.5 and 6 , with no digestive function possible.
In Group 3, with ulceration, the patients yielded volumes of secretion which varied within wide limits, but were often profuse, in which case the mucus content was low, and the juice had an unusual serous consistency and colour. Pepsin concentrations were high and often hypersecretory. With but two exceptions, the $p \mathrm{H}$ was well capable of activating pepsin ; in these exceptions, frequent attacks of vomiting occurred during the day, which may have been responsible for this grade of damage, whereas, from their nocturnal juice activity alone, these patients would have fitted the lower grade.

In Group 4, with inflammation or stricture involving the wall of the oesophagus, there were similar findings to the previous group, except in two cases, when the stenosis was so extreme that reflux was limited, and a pool of protective alkaline saliva retained above the stricture made the overall $p \mathrm{H}$ of the juice fall outside the limits of activation. These were the only two cases in the group which showed this high mucus and low acid content; all the rest presented the same serous kind of juice associated with severe damage, as previously mentioned.

Towards the end of this study fresh attention was directed to the bile content of the reflux juice, for traces appeared in only $8 \%$ of the tests, while normal fasting gastric juice is green in 60 to $70 \%$ of individuals (Babkin, 1950). Moreover, bile was often seen in the gullet at oesophagoscopy when it was absent from the night juice. This suggested that night reflux might be limited by the diaphragm. And, to test this idea, gelatin capsules of carmine red dye $(0.25 \mathrm{~g}$.) were given just before the patient settled down to sleep. When wet, these disintegrate within two minutes at body temperature, staining the night-time gastric contents bright red for approximately six hours, yet no trace of dye has been recovered with the oesophageal juices when the dye indicator was used (Fig. 6). This

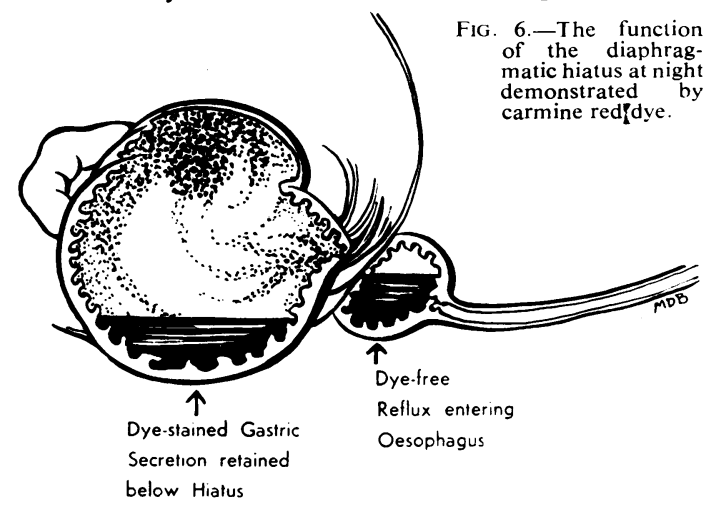

below Hiatus 


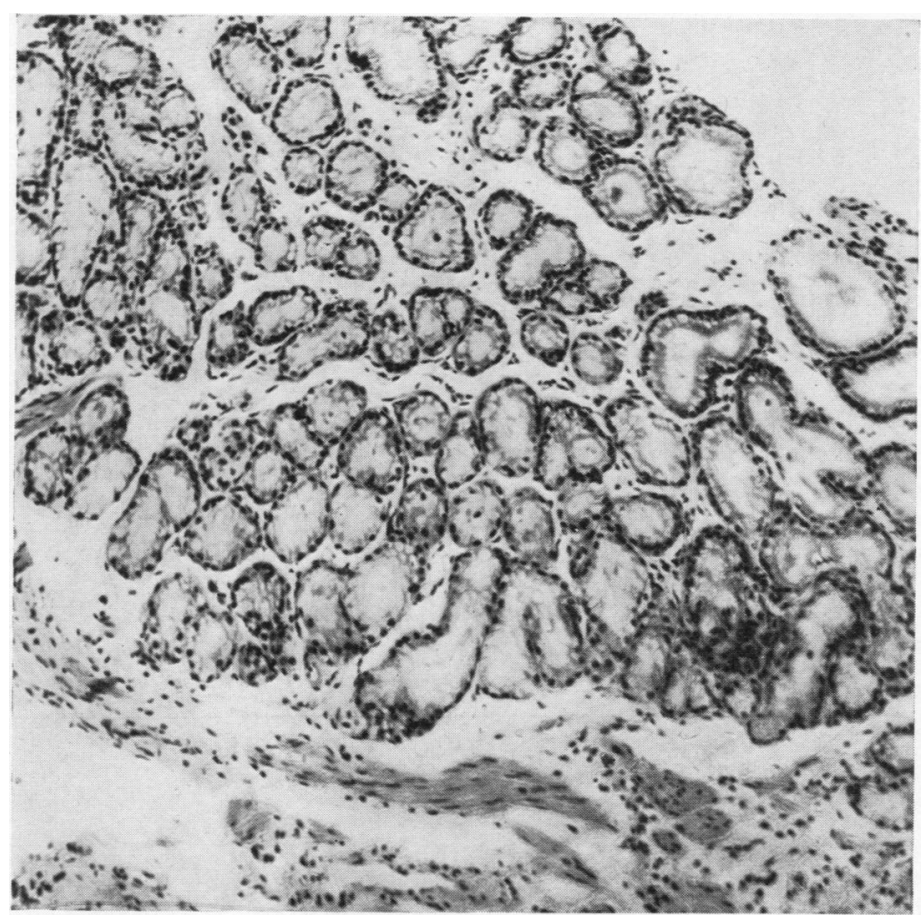

FiG. 7.-Three endoscopic biopsies taken approximately $1 \mathrm{~cm}$. below the oesophago-gastric junction: (a) no oesophagitis, cardiac mucosa; (b) moderate oeso. phagitis, enzyme cells but few oxyntic cells; (c) ulcerative oesophagitis, plentiful enzyme and oxyntic cells.

to carry out its protective function with great efficiency, for day-time damage remains slight.

At night, when the patient lies still and peristalsis is minimal, it is within the powers of the hiatus to resist feeble changes in gastric pressure, and so keep below the diaphragm the secretions of the main part of the stomach. With the patient flat the secretions from the mucosa of the pouch remain above the hiatus, oozing past the incompetent cardia all night to digest the epithelium of the oesophagus at leisure, with no salivation to oppose it. With deep sleep, the warning pain of heartburn may fail to waken the patient, who would otherwise be sitting up and swallowing saliva or a glass of milk to stop the erosion. The benefit gained from sleeping upright is obvious, for then the hernia must fill slowly limitation of reflux at night is important in recognizing the mechanism which causes different degrees of damage in different patients.

\section{Physiological Conclusions}

Day aNd Night RefluX.- It appears that two kinds of reflux occur in all patients suffering from sliding hiatal hernia. During the day-time any part of the stomach contents can be pushed upwards by exertion of peristalsis, only to fall back as gastric pressure drops. Heartburn follows if a high acid content stings raw areas of squamous epithelium, and this pain starts the excessive salivation which most observant patients describe. The film of digestive juice still clinging to the oesophageal wall is dealt with by protective salivary mucus, which increases the $p \mathrm{H}$ so quickly that pepsin is inactivated before it has time to damage the vulnerable tissues seriously. The normal salivary output is 1.5 litres per day, or $100 \mathrm{ml}$. in each waking hour, but with repeated reflex stimulation it becomes many times this amount and able

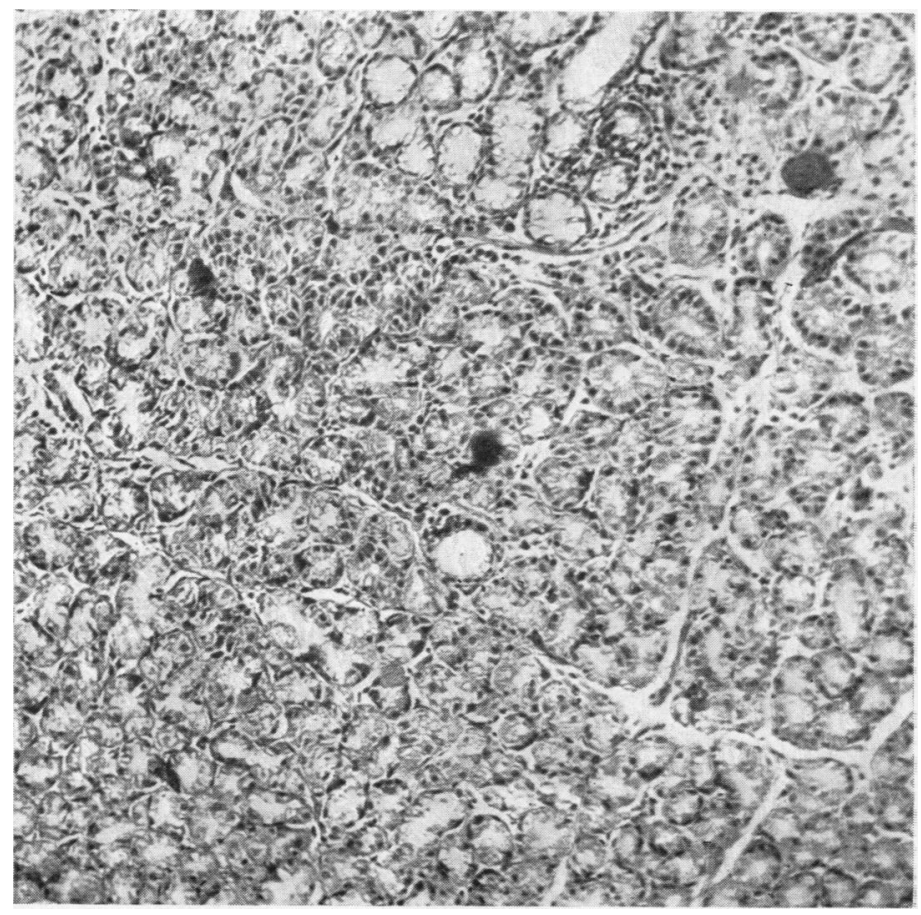

FiG. $7 b$. 


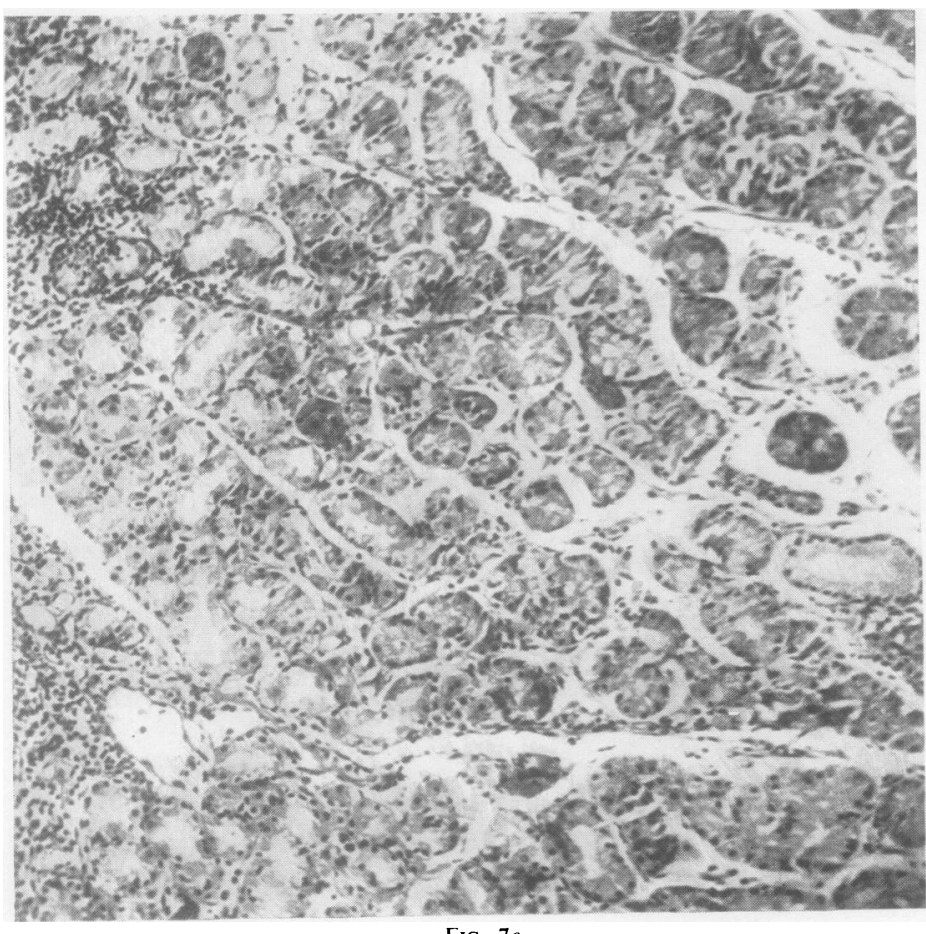

FIG. $7 c$.

for some hours before juice reaches the gullet. The above picture, suggesting that night-time juice, with its prolonged action, sets the pace of oesophageal damage, is supported in the series, first, by the close correlation observed between these two, and, secondly, by the fact that only the mildest damage is seen in the gullet from day-time reflux when there is no peptic activity at night (Groups 1 and 2, which include $60 \%$ of the series). Special factors may alter this one-sided balance towards greater day-time damage ; gastric obstruction, vomiting, stooping and lifting at work, straining by cough, constipation, or corsets, will all add their quota. But patients of this series already knew how to avoid these aggravating factors a long time before their juice was tested, so good correlation remained undisturbed, except in the patients who vomited.

The Cardiac "SPhincter."-Rather unexpectedly juice tests yielded no secretion in 13 subjects or $26 \%$ of the series. All these came from patients in Group 1 with no visible oesophagitis, and were always confirmed by repeating the test. This shows that some sliding hiatal herniae are free from incompetence at night. Reduction of the pouch during sleep is not the cause, since dry tests occurred alike with small or large herniae which obviously remain in the chest when the patient is flat and completely relaxed during radiological screening. It is more likely that the cardia sometimes retains a degree of competence in spite $\frac{\vec{D}}{\overrightarrow{0}}$ of its displacement above the dia- ¿ phragm. This suggestion fits well the experimental findings summarized by $\vec{\circ}$ Alvarez (1950) concerning the intrinsic neuromuscular power of reflex contrac- $\vec{\omega}$ tion at the cardia, which is independent of the diaphragm. It also has a bearing on the work of Allison (1951) concerning the technique of repair, for $\vec{\omega}$ when a stricture has formed this intrin- $\infty$ sic mechanism is destroyed, and though 윽 surgical reduction may yet be accomplished it fails to cure reflux and so progressive damage continues. It is not clear why uncomplicated herniae often lose this mechanism at the cardia. It 0 could be due to inflammatory changes, $\omega$ or to mechanical distortion of this delicate muscular ring. As the cuff of phreno-oesophageal fascia attached to the cardia is repeatedly stretched by the hernia, any vascular or fibrous anchor- $\mathbb{D}$ age within it could cause uneven trac- $\overrightarrow{\vec{F}}$ tion, or simple stretching may result in gradual $\frac{0}{3}$ loss of power. Whatever the cause, the loss of $\frac{3}{\vec{T}}$ this mechanism represents an early but serious step in the development of progressive damage, for until it is lost the patient is free from oesophagitis in spite of the hernia.

SALIVARY PROTECTION.-Examination of oesophageal juice has indicated how the gullet receives? partial protection against the damaging reflux that $\frac{0}{3}$ reaches all levels up to the mouth. The salivary and oesophageal secretions can inhibit the pepsin을 mechanism in two ways: by buffering acid, and by $\frac{7}{0}$ slowing down the activity of pepsin. These secretions usually restrict the site of maximal damage $N$ to a well-defined region just above the cardia, $N$ which is unprotected because the defence lineo created in the gullet becomes gradually weakerc as the cardia is approached. Should the damaged area extend higher than usual the cause is increas ing disproportion between these opposing forces, $\mathbb{D}$ and the indications for surgical repair of the herniawill be increased unless there is an aggravating factor which can be stopped. For example, an extreme form of universal oesophagitis with acutes dysphagia is sometimes seen above a previously silent hernia when dehydration from severe illness్ suppresses salivation completely. The condition 
subsides with rehydration of the patient, because then salivation returns and defence is restored.

Oesophageal Secretion.-Using the oesophageal tube, it can be shown that in health the oesophagus produces no secretion at night. This was so in a series of normal patients used as controls, as well as in the group with no oesophagitis which contains 13 dry tests. However, in combating reflux, the part played by the oesophageal glands is important, because they become the principal defenders of the oesophagus at night when salivation ceases. At this time any changes in the mucus content of the juice must originate from the oesophagus or hernia. The thin, serous juice obtained with severe ulceration is not like any type of gastric juice, and it has a pale yellow colour not due to bile or blood. From work already done on the oesophageal glands (Vineberg and Komarov, 1933; Goetsch, 1910), it seems likely that the following explains most of the changes that occur in the consistency of oesophageal juice, though some remaining changes must be related to the variable gastric contribution.

The oesophageal glands which secrete at $p \mathrm{H}$ 7.5-8.2, and have a mixed salivary construction, are controlled by the vagus, yielding thick mucus when it is stimulated mildly, but profuse serous lubricant when stimulated strongly. Mucus, absent from the juice when there is no oesophagitis, is plentiful with minimal damage and is replaced by a lot of serous fluid with oesophageal ulceration. The oesophageal glands are quiescent in the first instance, but in the second and third the secretion resembles the two kinds evoked by moderate and strong vagal stimulation respectively. The normal function of serous secretion by the gullet is to protect it from swallowed noxious material, or excoriation by hard food, but, when arising from stimulation by multiple small ulcers, it represents replacement of active mucoid defence by passive watery dilution that has poor buffering qualities. Thus, with severe ulceration, night-time defence is weakened on two accounts, salivary and oesophageal, so the damage is correspondingly increased and more liable to be progressive.

Gastric Hypersecretion.-As continued irritation of the oesophagus causes reflex salivary and oesophageal hypersecretion, it is not surprising that with severe ulceration evidence of gastric hyperactivity is also found at night, when normally the stomach produces only inactive basal juice in small amounts. Such basal juice is obtainable from simple gastric fistulae free from disease (Beaumont, 1833 ; Wolf and Wolff, 1947), but the high values recorded in some published works on nocturnal gastric activity in relation to duodenal ulcer are most misleading, because they neglect the vagal secretion caused by the presence of a rough rubber collecting-tube in the throat. It is not surprising that under such circumstances "normals" yield as much hypersecretion as patients with duodenal ulcers. In this series are 16 patients with chronic nocturnal gastric hypersecretion of oesophageal origin, yet not one has a duodenal ulcer, which fact leaves little doubt that different factors must be responsible for duodenal damage. The gastric hyperactivity in these 16 patients is important because, once established, it becomes progressive by causing more damage and more hypersecretion from the stomach. This vicious circle continues unless the defence system can cause its breakdown.

Histology of The Pouch.-Most of the factors discussed so far are those which modify the effects of active juice once it has reached the oesophagus, either protecting it or encouraging progressive damage. However, the principal factor which decides the balance of power is always the peptic activity that the pouch can produce alone, and this remains constant, as does the average level of damage, for each patient over long periods of time. Therefore it seems reasonable, when looking for the cause of variable prognosis in these patients, to seek it in the distribution of the various glandular elements that go to make up this mucosa. Unfortunately, direct histology is denied to us in these patients, for reduction of the hernia leaves no material available, except endoscopic biopsies which are inadequate for the purpose. However, commonplace and sufficiently wide variations in the mucosal structure at the cardiac end of the stomach have been described in the literature, and seem acceptable, as indirect evidence, for a theory which fits the rest of the findings of this study on the oesophageal juice, to explain the capricious development of oesophagitis.

Plenk (1932) observed that in man the zone of cardiac glands may vary in width between 0.5 and $5 \mathrm{~cm}$. As few herniae rise more than 6-8 cm. above the hiatus, these glands may supply a large part of the total secretion from the pouch. Bensley (1902), who described the morphology of these glands in mammals, found their development with different species extremely wide and may explain why it remains irregular in man. He also decided that these simple tubes, which secrete neutral or alkaline mucus, are decadent digestive glands, which have failed to specialize in the production of enzyme and oxyntic cells; however, both these cell types do appear amongst the cardiac 
zone in different specimens to some extent, so their secretion may not be entirely devoid of peptic activity.

Below the cardiac zone the digestive glands show an orderly change in the ratio of peptic cells to oxyntic cells from the upper part where peptic cells predominate to the lower where oxyntic cells predominate (Billenkamp, 1929). The first $3 \mathrm{~cm}$. of this zone usually contain few oxyntic cells (Brenckmann and Deloyers, 1929a and b), and when isolated from the rest of the stomach by the hiatus may provide plenty of pepsin but insufficient acidity for its activation. This kind of juice is common in the group with minimal damage. The above normal plan of distribution is often varied (Berger, 1934), and oxyntic cells may be found in profusion right up to the cardiac zone. Such a state of affairs has been observed in biopsies taken from just below the oesophago-gastric junction in some of our severe cases of ulceration (Fig. 7). Fig. 8 shows how the glandular elements were distributed in the hernia of a patient who required resection for peptic stenosis.
These facts about the variable development of peptic function in that area of stomach which gives $\stackrel{S}{\sigma}$ rise to all usual sizes of sliding herniae complete the background picture of this study on oesophagitis, and from it several further points arise. A little pepsin goes a long way in its active form, so a small hernia can produce a lot of damage if it contains the right kind of cells. And this is not an uncommon finding. Likewise, a large hernia may have no peptic mucosa, and the damage above it is only that which free day-time regurgitaticn can produce alone. Outside this series a few herniae with no oesophagitis have been seen in patients with chronic duodenal ulcers and hypersecretion. This difficult combination is explained by absent $\underset{\infty}{\omega}$ vomiting, and pouch mucosa with no peptic acti- 은 vity. As a given hernia becomes larger with age, obesity, or pregnancy, so its total nocturnal peptic $\bar{z}$ area will increase and account for the aggravated symptoms that such patients have. If this enlargement is reduced by dieting or parturition the grade $\overrightarrow{0}$ of damage immediately recedes. The elderly $\omega$ patients, however, continue to have steadily

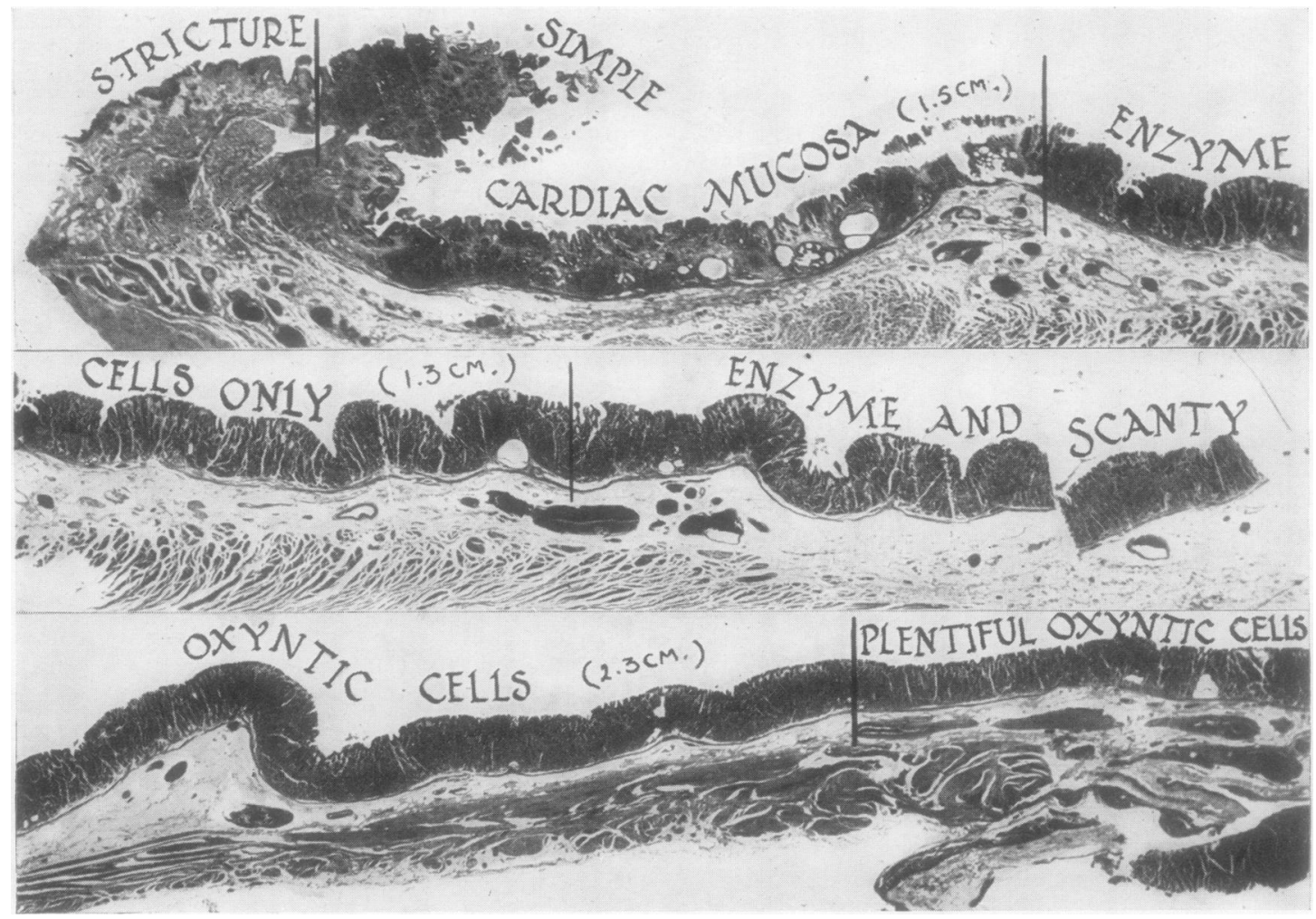

FIG. 8.-Longitudinal section through the hernia of a patient requiring resection for peptic stricture. 
increasing symptoms, and need surgery long after they have ceased to be a good operative risk.

Synthetic Herniae.-Oeosophago-gastrostomy is commonly used to restore continuity after resection of the cardia, but leaves a situation similar to hiatus hernia. Digestive epithelium is brought into the chest, with free reflux allowed by an artificial hiatus scarred from surgery, and though the vagi are divided all grades of peptic damage can be seen in the gullet and a proportion of strictures is inevitable. It would have been useful to investigate this type of oesophagitis on the same lines as this series of herniae, but such a poor opinion of oesophago-gastrostomy is held in Leeds that no patients are available.

In conclusion, it is not recommended that oesophageal juice testing should be applied clinically ; it requires much painstaking personal attention to detail, and merely parallels the results of nakedeye observation through the oesophagoscope. However, it was fundamental in gaining information about this complex picture of disturbed physiology in the gullet, which can now be called "peptic" oesophagitis with every justification.

\section{SUMmary}

The damage found above a hiatus hernia is directly related to the enzyme activity of the juices bathing the oesophagus at night. This varies from basal levels to gastric hypersecretion in different individuals. Reflux during sleep differs from that occurring freely during the day, first, because it arises only from the mucosa of the hernia, while the remaining stomach juice is excluded by the hiatal margins ; and, secondly because salivation, the mainstay of oesophageal defence, is absent at night, so slow peptic digestion continues almost undisturbed. During the day, however, reflux is quickly neutralized and damage is slight unless the mucoid protective mechanisms are impaired or overwhelmed.

In the early stages of its development a hernia may have above it a cardia which remains sufficiently competent to prevent nocturnal reflux. Then oesophagitis does not occur until this competence is lost and night-time juice is released to do its evil work.

The different steady grades of oesophagitis in hiatus hernia can be explained on the combined basis of variations of the histological structure and function in that part of the stomach which forms the hernia and the vagal overactivity which accompanies severe damage. The origin of this vagal activity might be constitutional, but it seems more likely that, once established, severe oesophagitis produces vagal irritation responsible for increased salivation and oesophageal and gastric secretion. The first two are protective, but the gastric hypersecretion is not, and continues even at night to form a vicious circle ending in peptic stricture, provided sufficient digestive elements are present in the epithelium of the pouch.

\section{REFERENCES}

Allison, P. R. (1951). Surg. Obstet. Gynec., 92, 419.

Alvarez, W. C. (1950). An Introduction to Gastro-enterology, 4th ed.,

p. 317. London.
Babkin, B. P. (1950). Secretory Mechanism of the Digestive Glands, 2nd ed., p. 208. New York.

Beaumont, W. (1833). Experiments and Observations on the Gastric Juice and the Physiology of Digestion. Plattsburgh.

Bensley, R. R. (1902). Amer. J. Anat., 21, 105.

Berger, E. H. (1934). Ibid., 54, 87.

Billenkamp, H. (1929). Beitr path. Anat, 82, 475.

Brenckmann, E., and Deloyers, L. (1929a). C.R. Soc. Biol., Paris, 102, 29.

- - (1929b). Presse méd., 37, 1086.

Fuld, E., and Levison, L. A. (1907). Biochem. Z., 6, 473.

Goetsch, E. (1910). Amer. J. Anat., 10, 1.

Mathews, A. P. (1925). Physiological Chemistry, 4th ed., p. 1030. London.

Plenk, H. (1932). In Möllendorff Handbuch der Mikroskopischen Anatomie des Menschen, vol. 5, pt. 2, p. 172. Berlin

Selye, H. (1938). Canad. med. Ass. J., 39, 447.

Vineberg, A. M., and Komarov, S. A. (1933). Amer. J. Physiol., $104,73$.

Wolf, S.. and Wolf, H. G. (1947). Human Gastric Function, p. 44. London. 